\title{
DOIS PAÍSES, MUITAS INFÂNCIAS: ENCONTROS PARA CRIAR COM OS FILMES CARRETO E UNA NIÑA UNA ESCUELA
}

\author{
FERNANDA OMELCZUK* \\ Universidade Federal de São João del-Rei, Brasil \\ fernandaow@ufsj.edu.br \\ MARICela Perera Pérez $z^{* *}$ \\ Instituto de Investigaciones de la Cultura "Juan Marinello", Cuba \\ maricelaperera@gmail.com
}

Recibido: 21/5/2020 Aceptado: 03/8/2020

DOl: https://doi.org/10.26439/contratexto2020.n034.4874

Resumo: Stephanie e Laura são duas meninas que se encontram na singularidade de um modo de existência que nem sempre tem espaço no cotidiano da vida e das escolas. Tinho é sensível em perceber as necessidades de Stephanie como intrínsecas à de qualquer criança. Assim, nasce entre eles uma silenciosa e cúmplice amizade. Laura tem, em sua família e no coração das políticas do país onde nasceu, o reconhecimento de que todas as vidas importam. Todo esforço é válido, portanto, para fazer funcionar uma escola que atenda a uma única criança. A partir da metodologia de análise da criação das imagens dos curtas brasileiro, Carreto, e cubano, Una niña una escuela, o artigo destaca o modo respeitoso com que os diretores constroem a relação das crianças com necessidades educacionais especiais e seu entorno. 0 resultado dessa análise permitiu compartilhar, no contexto da Lei 13.006/2014, exercícios de criação, a partir desses dois filmes. Os exercícios que o artigo propõe, inspirados na metodologia da pedagogia da criação, podem ser desenvolvidos com crianças; e tem o objetivo de destacar as infâncias brasileiras e latino-americanas, e potencializar a relação inventiva com o audiovisual.

Palavras-chave: cinema e educação / infância e cinema / educação e inclusão / exercícios de criação / cinema e América Latina

\footnotetext{
* Doutora em Educação pela Universidade Federal do Rio de Janeiro (UFRJ) (https://orcid.org/0000-00028617-8971).

* Doctora en Ciencias Psicológicas por la Universidad de La Habana, Cuba (https://orcid.org/0000-00023418-3007).
} 


\section{DOS PAÍSES, MUCHAS INFANCIAS: ENCUENTROS PARA CREAR CON LAS PELÍCULAS CARRETOY UNA NIÑA UNA ESCUELA}

Resumen. Stephanie y Laura son dos chicas que se encuentran en la singularidad de una forma de existencia que no siempre tiene un lugar en la vida cotidiana y en las escuelas. Tinho es sensible a percibir las necesidades de Stephanie como intrínsecas a las de cualquier niño. Así, una amistad silenciosa y cómplice nace entre ellos. Laura tiene en su familia y en el corazón de las políticas del país donde nació el reconocimiento de que todas las vidas importan. Por lo tanto, todo esfuerzo es válido para operar una escuela que atiende a un solo niño. A partir de la metodología de análisis de la creación de imágenes de los cortos Carreto (brasileño) y Una niña una escuela (cubano), el artículo destaca la forma respetuosa en que los directores construyen la relación de los niños con necesidades educativas especiales y su entorno. El resultado de este análisis permitió compartir, en el contexto de la Ley 13.006 / 2014, ejercicios creativos, basados en estas dos películas. Los ejercicios que propone el artículo, inspirados en la metodología de la pedagogía de la creación, pueden ser desarrollados con niños, y tienen como objetivo resaltar la infancia brasileña y latinoamericana y potenciar la relación inventiva con el audiovisual.

Palabras clave: cine y educación / infancia y cine / educación e inclusión / ejercicios creativos / cine y Latinoamérica

\section{TWO COUNTRIES, MANY CHILDHOODS: MEETINGS TO CREATE WITH THE FILMS CARRETO AND UNA NIÑA, UNA ESCUELA}

Abstract. Stephanie and Laura are two girls who find themselves in the uniqueness of a mode of existence that does not always have space in everyday life and schools. Tinho is sensitive enough to perceiving Stephanie's needs as intrinsic to any child's. Thus, a silent and complicit friendship is born between them. Laura recognizes-in her family and at the heart of the politics of the country in which she was born-that all lives matter. Every effort is therefore valid to run a school that caters for a single child. Based on the methodology for analyzing the creation of images from the Brazilian short Carreto and the Cuban short Una niña, una escuela, the article highlights the respectful way in which the directors build the relationship of children with special educational needs and their surroundings. The result of this analysis made it possible to share, in the context of Law 13.006/2014, creative exercises based on these two films. The exercises proposed by the article, inspired by the methodology of creation pedagogy, can be developed with children, and aim to highlight Brazilian and Latin American childhoods, as well as to enhance the inventive relationship with the audiovisual material.

Keywords: cinema and education / childhood and cinema / education and inclusion / creative exercises / cinema and Latin America 


\section{BREVE INTRODUÇÃO - PARA IR DIRETO AO ENCONTRO}

Há uma pauta crescente de discussões entre educadores, pais e profissionais da mídia sobre a relação das crianças com as imagens e o audiovisual, especialmente sobre a influência que estes exercem sobre os gostos, pensamentos e comportamentos infantis. Em paralelo, vêm se multiplicando as pesquisas sobre transformações narrativas, linguísticas e cognitivas advindas da presença massiva das imagens no cotidiano, dos impactos das novas tecnologias e dos desafios para a escola construída sob os pilares modernos da escrita.

Nesse contexto, os assuntos, os conteúdos e as histórias dos filmes se mostram sempre como um recorte significativo para a escolha e exibição para as crianças, seja nos ambientes domésticos ou nos contextos educativos. Os curtas brasileiro Carreto (2009), de Cláudio Marques e Marília Hughes, e cubano Una niña una escuela (2008), de Alejandro Anderson, são facilmente identificados como obras que sugerem trabalhos abordando o tema da "inclusão".

0 motivo pelo qual escolhemos pensar sobre eles, entretanto, não se limita à sua temática, mas ao modo como os diretores a abordam. Compartilhamos com Bergala (2008), portanto, um estranhamento acerca da pouca preocupação com a dimensão estética nos produtos audiovisuais que exibimos para as crianças. Há um medo de que o cinema "pode ser perigoso, o perigo ideológico. 0 medo de valores nefastos que o cinema pode ser portador (violência, racismo etc.), mas não se tem medo da mediocridade e da nulidade artística" (Bergala, 2008, p. 45).

Esse posicionamento se aproxima da análise realizada por Fresquet (2013). Dentre as diferentes definições de cinema apontadas por Aumont e Marie (2012): substituto do olhar, linguagem, escrita, pensamento, manifestação de afeto, simbolização do desejo e arte; Fresquet (2013) destaca que a perspectiva do cinema como arte é a mais ausente no campo da educação, o que faz com que muitas vezes tenhamos uma monotonia na estética das imagens e nos assuntos, que não dão conta da diversidade de vidas e modos de se expressar.

Ao ressaltar isso, situamos o lugar de onde partimos ao escolher essas duas obras com o objetivo de pensar a seleção de filmes para exibição dentro e/ou fora da escola e o trabalho pedagógico com eles, sensíveis à regulamentação da Lei 13.006/2014 e à escassez de imagens que representem a diversidade de infâncias brasileiras e latinoamericanas, imagens que aproximem as crianças da produção cultural de seu próprio país, de sua cultura e de suas realidades.

1 A Lei 13.006/2014 modificou o artigo 26 da Lei 9395/1996 acrescentando a seguinte redação: “A exibição de filmes de produção nacional constituirá componente curricular complementar integrado à proposta pedagógica da escola, sendo a sua exibição obrigatória por, no mínimo, 2 (duas) horas mensais". 
Atualmente, a apresentação de filmes nacionais nas escolas brasileiras é uma política de obrigatoriedade por, no mínimo, duas horas mensais - conforme a Lei13.006, de 26 de junho de 2014. Ainda que sem regulamentação, ela inspira e fornece fundamentos para diversas ações com o audiovisual que acontecem isoladamente nos espaços educativos.

Em 2009; reconhecendo o número crescente de ações em cinema-educação na América Latina, a necessidade de intercâmbio sobre as diferentes práticas e metodologias, e a dificuldade de articulação entre educadores, pesquisadores, cineastas e produtores para superar a distância entre produção artística e formação humana; as professoras Inês Assunção de Castro Teixeira (UFMG), Milene de Cássia Silveira Gusmão (UESB), Rosália Duarte (PPGE/PUC-Rio) e Adriana Fresquet (PPGE/UFRJ), e também as professoras Bete Bullara e Marialva Monteiro (CINEDUC-RJ), convocaram os demais grupos de pesquisas e cineclubistas a consolidarem a Rede KINO (Rede Latino Americana de Educação, Cinema e Audiovisual). Além de encontros regionais ao longo do ano, os Fóruns nacionais da KINO acontecem desde 2010 dentro do Seminário de Educação da Mostra de Cinema de Ouro Preto (CineOP).

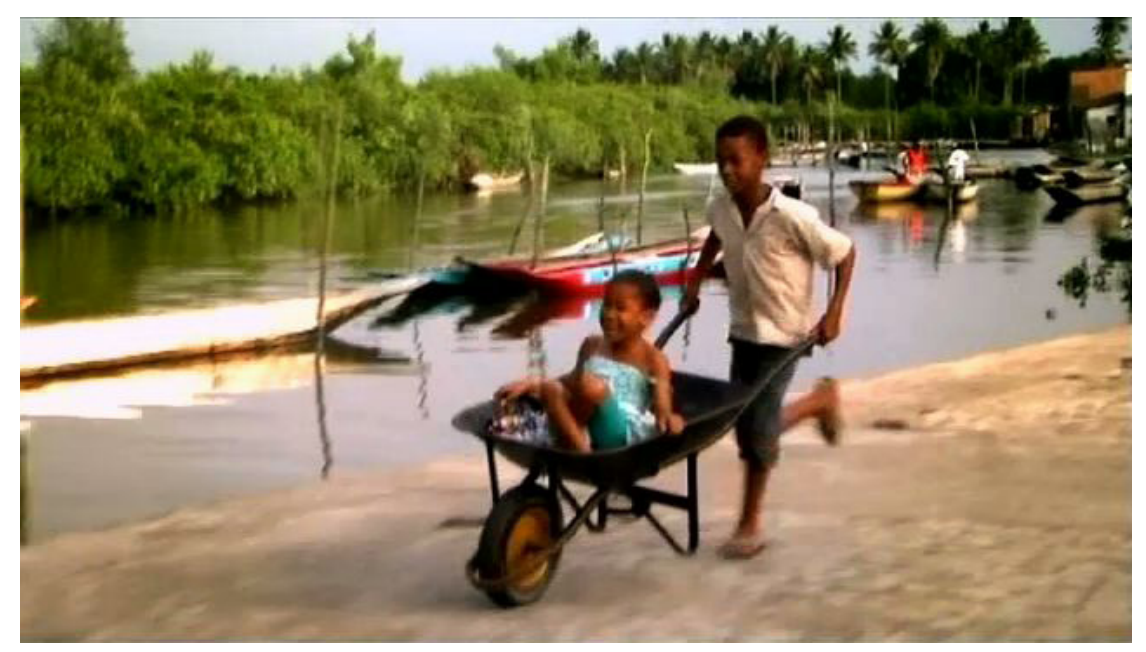

Figura 1. Fotograma do curta

Fonte: Carreto (2009) 


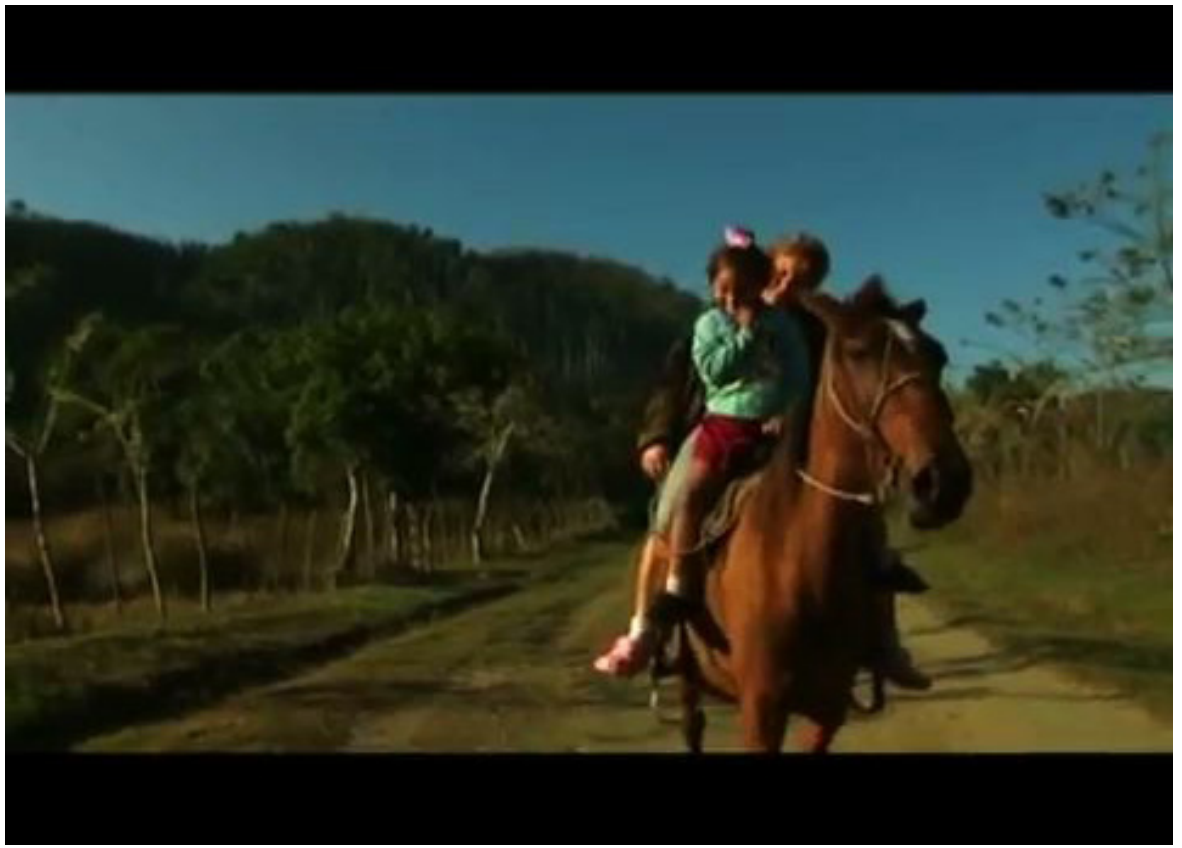

Figura 2. Fotograma do curta

Fonte: Una niña una escuela (2008)

Entendemos, apoiados em algumas teorias do cinema (Alea, 2009; Comolli, 2008; Daney, 2007; Eisenstein, 2002; García Espinosa, 1970), que as imagens cinematográficas são um modo de pensamento, as quais criam modos de relação e imaginários sobre a realidade que inventam o mundo, especialmente pelos recursos expressivos que o diretor utiliza: a posição que enquadra, o tempo que dá a ver o mundo que filma, a composição das imagens filmadas e o modo como articula som e imagem. Esses elementos compõem uma estética e, consequentemente, uma política do olhar.

Que infâncias são vistas nos filmes a que as crianças comumente assistem? Será que elas se reconhecem nas imagens comercialmente divulgadas? Que crianças hegemonicamente predominam nos produtos audiovisuais destinados às crianças latino- americanas?

No contexto educativo, selecionar filmes é uma tarefa de dimensão estética e política, porque diz respeito à manutenção ou não de uma hegemonia sobre aquilo que se vê, se pensa e se sente. Nesse aspecto, apostamos em um encontro do cinema com a educação e com as infâncias como regime estético, em que o mundo inventado da tela afete as formas de sentir e se relacionar com o outro (Rancière, 2009). 
Quais imagens de crianças, de Brasil, de América Latina e de modos de ser são expressas nos filmes aos quais as crianças têm mais facilmente acesso? Nas linhas a seguir, percorreremos por dois curtas-metragens latino-americanos (um brasileiro e outro cubano) que consideramos para afirmar vidas, relações e subjetividades que pouco circulam dentre as imagens audiovisuais de circuitos comerciais. A construção do cotidiano de Stephanie e Laura é feita sem exageros, sem condescendência nem sentimentalismos caridosos acerca da condição física e/ou cognitiva das meninas, que abre espaço para a amizade e o apreço com o outro, o que parece ser, nos dois filmes, uma postura de respeito e apreço pela vida acima de qualquer coisa.

Para a análise dessas imagens e a proposição das atividades que faremos ao final do texto olhamos para as crianças filmadas, a partir das proposições de pensadores da infância como Agamben (2007) e Benjamin (2002) e nos amparamos principalmente na metodologia da criação de Bergala (2008). Essa metodologia entende que as imagens cinematográficas não são fruto exclusivo de decisões prévias, neutras e de objetivos determinados pela linguagem do cinema. Uma analise da criação inclui a intuição, a sensibilidade e os afetos (éticos e políticos) como parte do processo da filmagem que se expressa em três gestos fundamentais: a eleição, a disposição e o ataque. Eleger implica as escolhas que o diretor precisa fazer durante todo processo de produção do filme, nas filmagem, montagem e mixagem. Escolher desde as cores que as personagens vão vestir até a locação das cenas, os cortes. A disposição implica estabelecer uma relação entre essas coisas: os elementos do cenário, os objetos, os figurantes e determinar a ordem relativa dos planos filmados. 0 ataque envolve a decisão do ângulo ou do momento preciso para iniciar a filmagem. 0 diretor precisa decidir o ataque da câmera em termos de distância, de eixo, de altura, de objetiva e dos microfones.

0 modo como um enquadramento é construído, um plano é filmado e a imagens chegam até nós são resultados desses três gestos que ao final geram o filme como um todo, sem dissociar tema, ética, estética, política. Estética é sempre conteúdo. Conteúdo político.

Analisamos os filmes desde um ponto de vista da criação porque acreditamos, como já apontamos acima, na política intrínseca à estética, presente nos modos de fazer e ver, mais do que exclusivamente nos temas tratados. Por este motivo, as atividades que elaboramos também se focam em processos criativos, capazes de afetar a sensibilidade, os pensamentos e as ideias que nos atravessam sobre o modo de vida das crianças filmadas. 


\section{CARRETO | BRASIL | 2009}

Carreto está disponível na Internet em versão com $A D^{2}$ (audiodescrição), o que faz do objeto filme em si uma ação de afirmação e inclusão. Suas primeiras imagens nos inserem no universo do menino, marcado por um entorno de riquezas naturais que os planos destacam em enquadramentos fotográficos, valorizando cores, reflexos, sombras, texturas e sons. Tinho trabalha oferecendo transporte com seu carrinho de mão além de atender a outras tarefas que executa com destreza, como a subida em árvores para colheita de cajus.

Nas primeiras cenas, ele acompanha uma senhora na busca por mariscos em uma região de mangue. Logo após, ele a segue com seu carrinho até uma casa simples e, pela janela aberta da casa, percebe desenhos coloridos na parede. Ao entrar no quintal, depara-se com uma menina de olhar doce, que está sentada diante de uma mesa com papéis e lápis coloridos.

A senhora the pede que esvazie o carrinho carregado de mariscos e pergunta se ele sabe catar caju, no que ele responde sim. Enquanto desata o nó dos sacos cheios de mariscos, nota algo que se parece com rodas de bicicleta ao seu lado. 0 filme sugere algo, mas ainda não nos revela completamente do que se tratam essas rodas. Com planos simples e silenciosos, conhecemos um menino observador, atento e sensível, e continuamos a vagar pelo filme com seu olhar curioso.

0 encontro com Stephanie acontece ao voltar da colheita dos cajus. Enquanto tira os frutos do carrinho e os coloca num balaio, ele olha para a menina sentada no chão do pátio. Ela levanta meio corpo com as mãos e engatinha rastejando um pouco suas pernas até um banco de madeira. Num impulso com as mãos, levanta-se. Vemos seus pezinhos pouco firmes se arrastando de lado acompanhando o banco. Ela cai e sorri, levanta e continua caminhando.

Tinho a observa sério. Olha para as rodas que havia visto antes. Vemos, então, com ele, que se trata de uma cadeira de rodas velha e quebrada. A menina o chama e the entrega um desenho: um menino segurando um carrinho de mão ao lado de uma árvore e dois barcos. Não há diálogos. Um sorriso tímido entre os dois. Uma amizade foi iniciada.

À noite, escondido, profanando o mundo adulto, Tinho coloca a cadeira de rodas em seu carrinho de mão e, antes ainda do raiar da alvorada, vai a diferentes oficinas à busca por conserto. Sem sucesso, retorna correndo para a casa da senhora, que o censura ao vê-lo chegar com a cadeira. 0 menino não sucumbe ao lugar de criança "travessa" que o mundo insiste em o colocar e a encara com um ar sério e compenetrado, suspendendo os lugares comuns que crianças e adultos costumam ocupar (Agamben, 2007).

2 Retirado de http://educa-tube.blogspot.com.br/2015/06/carreto-curta-metragem-sobre-inclusao. html 
Em seguida, no último plano do filme, um sorriso espontâneo nos invade ao ouvirmos as gargalhadas da menina e ao vermos Tinho correndo com seu carrinho pelas margens do rio com ela sentada dentro. A cena transmite orgulho e esperança acerca das potencialidades de profanação e reinvenção do mundo pela infância - expressas num olhar lúdico, sensível e refuncionalizador do uso dos objetos - atravessada pela experiência inventiva da criança (Benjamin, 2002).

\section{UNA NIÑA UNA ESCUELA | CUBA | 2008}

Una niña una escuela é um filme documentário, o qual entretanto, não repete padrões jornalísticos de entrevistas, depoimentos e explicações. 0 filme não tenta persuadir o espectador sobre seu ponto de vista de um modo panfletário, mas tampouco é neutro. Suas escolhas políticas estão explícitas, porém o argumento se constrói por meio de suas escolhas estéticas, e não com palavras ou diálogos para convencer o espectador. 0 tema não está à frente das imagens.

A primeira cena nos mostra uma menina carinhosa com uma mulher banhando-se em um rio. As cenas são intercaladas com planos de diferentes animais: porcos, cachorros e galinhas. 0 ambiente é de paz e tranquilidade, com um ritmo íntimo e rural. Há apenas duas legendas no filme: El Escambray, 2008 - num plano aberto do vilarejo - e Laura montada sobre um cavalo.

Vemos um povoado simples, com crianças envolvidas em atividades do cotidiano adulto com naturalidade, como na limpeza de um porco que acabara de ser sacrificado e no acompanhamento do deslocar de bois. Nas cenas seguintes, a aurora vai surgindo devagar: névoas, pequenos sons de animais e os primeiros raios de luz e cor. Um cavalo é preparado. A menina veste um uniforme escolar auxiliada por uma mulher adulta, talvez sua mãe. Desse modo, o diretor vai nos inserindo na atmosfera aconchegante de Laura.

A câmera nos mostra, então, o percurso de Laura e sua mãe sobre o cavalo até a escola, enquanto uma mulher - depois identificada como a professora -, também em um cavalo, transita por um caminho de montanha. Em seguida, cenas da chegada de Laura à escola, o encontro carinhoso com a professora e imagens das aulas, em que, com métodos apropriados à condição de Laura, a professora a acompanha por caminhos de aprendizagem.

É sensível ao espectador a relação professor-aluno, próxima e afetiva, que nos revela uma forma de ensinar, com recursos e apoios simples, todavia necessários para um ensino transformador, que leva a menina, por seu ritmo peculiar, preparando-a para a vida de acordo com suas capacidades.

Como em todos os dias, como em todas as escolas, como todas as crianças, Laura retorna, então, ao fim do filme, para sua casa. 0 ritmo universal e particular da história nos aproxima da menina e de sua vida. Assim, as emoções que sentimos não nos prendem 
à vivência do particular visto e experimentado, e sim nos conduzem a ressignificar ideias e valores universais.

Apostamos que sons, imagens, gestos, enquadramentos e silêncios, que formam parte da criação cinematográfica, podem transformar aos poucos o modo de ver a multiplicidade humana, na qual todos têm direito à alegria e à ternura em suas relações. 0 cinema, como arte e tecnologia visual, tem a possibilidade de explorar a experiência de aproximação da alteridade e afirmar atitudes e modos de relação para uma convivência social diferente. Dessa forma, o cinema é universal não pelo que exibe de "acontecimentos comuns a todos nós" (Almacella, 2004, p. 73), mas pelo que exibe de "acontecimentos possíveis a se concretizarem com a gente" (Martínez-Salanova Sánchez, 2002, p. 124).

\section{ENCONTROS DE CARRETO COM UNA NIÑA UNA ESCUELA: ALGUNS ASPECTOS DA REALIDADE CULTURAL E PEDAGÓGICA NO BRASIL E EM CUBA}

Una niña una escuela guarda muitos encontros com Carreto. Além do tema da inclusão, os dois filmes se aproximam por seus cenários geográficos, seus modos de mostrar desfocados do verbal e a abertura de experiências. Ao curta cubano, soma-se o fato de nos revelar ao final um dado relevante sobre as escolas de montanha nesse país: há mais de 60 delas que funcionam normalmente para atender apenas a uma única criança.

Vale informar que a Educação Primária em Cuba está organizada em seis anos agrupados em dois ciclos: um de primeiro ao quarto ano e outro que inclui o quinto e o sexto anos. No primeiro, são ministrados conhecimentos essenciais de Espanhol e Matemática. Além disso, os alunos recebem noções elementares relacionadas à natureza e à sociedade e realizam atividades de educação física, laboral e estética. No segundo ciclo, incorpora-se o estudo de História e Geografia de Cuba, Ciências Naturais e Educação Cívica; também, desenvolvem-se atividades de educação patriótica, física, laboral e estética. A cobertura universal da educação básica se exemplifica com os seguintes dados: para o período 2008-2009, existiam 204 escolas rurais que atendiam a um só aluno (devido às regiões dispersas em certas zonas rurais do país); 294 atendiam a dois alunos; 313 atendiam a três; 315 atendiam a quatro; e 272 a cinco (MINED - Ministerio de Educación de la República Cuba, 2008). Trabalha-se para que criança alguma fique sem estudos básicos. Em Cuba, todas as crianças de zonas rurais e afastadas estão escolarizadas e frequentam mais de 4.580 centros de ensino primário e/ou instituições mistas. A existência desses centros educativos em suas regiões evita que os estudantes tenham que percorrer grandes distancias para estudar ${ }^{3}$.

3 Informações disponíveis em: http://www.sierramaestra.cu/index.php/titulares/9508-todos-losninos- escolarizados-en-zonas-rurales-de-cuba e http://www.rimed.cu 
Ainda que não haja, em Cuba, uma política oficial de cinema nacional em contextos educativos, como tivemos recentemente no Brasil com a lei 13.006/2014, vale lembrar que com o triunfo da Revolução Cubana em 1959, o cinema foi nacionalmente reconhecido como um poderoso meio de expressão para a formação da consciência individual e coletiva. Ampliar o acesso do público ao cinema, especialmente ao cinema produzido localmente, no contexto da América Latina, foi uma meta que a direção do Instituto Cubano de Arte e Indústria Cinematográficos - ICAIC - assumiu por meio da realização do cine-móvel, que levou o cinema até os lugares mais longínquos da ilha.

As sessões itinerantes de cinema foram às escolas, fazendas, sindicatos, fábricas, parques, associações de bairros e, inclusive, hospitais. De acordo com os dados levantados por Vilhaça $(2010$, p. 69) na década de 70 havia mais de 100 "unidades móveis" que levavam em jipes, mulas, barcos e até bicicletas o cinema para muitas pessoasque nunca o haviam visto antes.

Naquela época se fortaleceu, então, em Cuba a recusa ao cinema "comercial" e estrangeiro e a busca por temas regionais, autênticos e o desenvolvimento de uma estética própria, capaz de conjugar arte, política e transformação social. Passados mais de 40 anos, apesar da realidade da produção e distribuição da ltha atualmente atravessar crises, mudanças e de haver um desejo de acesso às produções comerciais americanas, ainda há proximidade e fácil acesso da população às suas próprias produções audiovisuais, como pode ser observado em uma pesquisa com crianças do Brasil e Cuba, em situação de internação hospitalar (Omelczuk, 2016).

Ao responderem sobre o último filme assistido, as crianças cubanas foram unânimes acerca da nacionalidade do último filme assistido: todos eram cubanos. Enquanto que, no Brasil, nenhum filme citado era brasileiro. De algum modo, esses dados revelam resultados positivos e duradouros de uma política protecionista que começa na infância. Entretanto, ainda que esta primeira informação guarde marcas do passado cultural de valorização do cinema cubano e da preocupação pela educação cinematográfica nesse país, vale destacar que quando perguntadas sobre seus filmes preferidos a realidade desses dois países se aproxima e revela uma homogeneização do gosto (Omelczuk, 2016).

Alegria e Duarte (2008) já chamaram atenção para isso em uma pesquisa anterior, onde constataram que as crianças brasileiras não reconheciam diferenças estéticas entre uma diversidade de filmes com propostas claramente distintas. Nomearam então as escolhas dos participantes como "mais do mesmo", isto é, uma pasteurização do gosto pelo acesso exclusivo a formatos muito semelhantes de quase uma única fonte cultural - a estadunidense. Segundo eles, a exposição das crianças a uma filmografia homogênea e hegemônica impede que percebam diferenças entre obras cinematográficas com propostas de linguagens (narrativas, rítmicas, estéticas, éticas, políticas) diferentes entre si e se tornam incapazes de formular uma avaliação qualitativa sobre o que veem. 
É por essas, dentre outras justificativas, que consideramos importante compartilhar propostas audiovisuais que rompam com padrões narrativos, linguísticos, estéticos e estilísticos já presentes no cotidiano comercial infantil. E, especialmente, que expressem realidades com as quais as crianças possam pensar a si mesmas. Não se trata de evitar o acesso a universos diferentes aos quais as crianças estão imersas, mas de pensar se o modo como essas alteridades estão construídas abre espaço para que pensem sobre as próprias realidades no Brasil, em Cuba, em toda América Latina, e que nelas se engajem. Entendemos que os curtas Carreto e Una niña una escuela possuem essa potência pedagógica, imagética e criativa.

\section{CARRETO E UNA NIÑA UNA ESCUELA: ENCONTROS REFLEXIVOS, IMAGÉTICOS E CRIATIVOS}

Diferentes gêneros nos mostram iguais possibilidades de um tratamento respeitoso e poético de temas cotidianos sem recorrer a formatos prontos e/ou comerciais e cenários espetaculares. Ambos exibem o fundamental sem excessos, sem emoções "pornográficas", cenas dramáticas ou teatralizadas, trabalhando sensações e argumentos com as imagens pelos meios de expressão propriamente cinematográficos (Bergala, 2012; Fresquet, 2013).

Estamos diante de duas obras audiovisuais que demostram sua condição de poderosa ferramenta cultural, uma aproximação aos espectadores de dissimiles aspectos da realidade mediante imagens e sons, que, de diversos modos, impactam o cognitivo e o emocional. Trata-se de criações audiovisuais que exibem - e criam - ideias e valores e nos convidam a refletir sobre o sensível tema das pessoas com necessidades especiais e as relações dos supostos "normais" e "diferentes". A maneira como abordam, para além dos recursos estéticos próprios de cada um, nos brindam uma forma de entender a diferença desde a ternura e os afetos infantis, mobilizando não só o racional e os sentimentos, mas vários sentidos ao mesmo tempo, porque, como afirma Jane Austen ${ }^{4}$ (2017), "o sentido do mundo só é captável por meio da combinação estratégica e amorosa da razão e da sensibilidade" (2017, p. 79).

Assim, entendemos que as imagens de ambos os filmes conduzem o espectador a descentrar o olhar do óbvio e da habitual e naturalizada atitude diante das pessoas com alguma dificuldade, que habitualmente é de exclusão e rechaço ou compaixão sentimentalista - igualmente desvalorizadora de tais pessoas. Os filmes em questão se distanciam desses estereótipos e preconceitos, levando-nos a mundos onde outras

4 Jane Austen (Inglaterra, 1875-1817) foi uma destacada romancista britânica, autora de Sense and Sensibility, título original em inglês, também conhecida em espanhol como Sentido y sensibilidad ou Sensatez y sentimentos, e em português por Razão e Sentimento. 
relações com a diferença acontecem e propondo-nos representações que produzem um "impacto sensível", são mobilizadores de sensações e sentimentos, ao mesmo tempo em que convocam à reflexão.

Ao filmarem cenas de um cotidiano trivial, que se repete na vida de todos nós, as imagens reforçam a impressão de realidade e carregam a potência de nos projetar nas situações dos personagens. Isso nos permite questionar as formas habituais de pensar, sentir, atuar e conceber o que é a diferença, ao mesmo tempo em que as imagens já afirmam outras maneiras de nos relacionarmos com a alteridade.

Adentramos o universo de crianças com necessidades especiais não sob o ponto de vista de que o diferente é o "outro" e que este deve ser tolerado e respeitado desde uma normatividade estabelecida. Talvez porque o olhar que nos conduza seja o da infância, os filmes nos convocam a formas originais de estar com o outro no sentido de que a primeira atitude é a presença, a escuta, a companhia. Sem recorrer para chantagens emocionais ou imagens sensacionalistas, Cláudio Marques, Marília Hughes ${ }^{5}$ e Alejandro Anderson ${ }^{6}$, diretores dos curtas em questão, abrem a experiência do espectador para o encontro com a diferença enquanto singularidade e manifestação das múltiplas possibilidades de ser humano (Bárcena, 2015).

Consideramos que o valor dessas propostas radica no intento de chegar ao espectador mediante a empatia com as situações e seus personagens, com o objetivo de afirmar uma alternativa que contribui para ampliar os horizontes do conhecimento cultural do espectador. Pela habilidade para conectar ideias e emoções, a fim de captar e manter o interesse, por propor um deslocamento de formas de relação e levar-nos, em definitivo, por caminhos sutis a assumir um modo outro de conceber e viver a diferença.

A partir dessas reflexões, queremos compartilhar alguns exercícios imagéticos e criativos que os curtas nos provocam a experimentar:

- como seria um encontro de Tinho (do filme Carreto) com Laura (do filme Una niña una escuela)? E de Laura e Stephanie (do filme Carreto)? Se Tinho chegasse ao filme de Laura, em que cena ele apareceria? Do que brincariam? 0 que fariam? Que tal brincar de ser diretor, sentir a emoção e as dificuldades da criação e inventar encontros entre os personagens dos dois curtas (professora, mãe e

5 Cláudio Marques e Marília Hughes se conheceram em 2004, na ocasião em que ele lhe ajudou a finalizar seu primeiro curta. Marília, além de cineasta, é psicóloga e filmou juntamente com Cláudio Marques seis curtas e um primeiro longa em 2012. Cláudio é um cinéfilo que nos anos 1990 abriu uma locadora de filmes VHS, colecionando clássicos pouco procurados.

6 Alejando Anderson nasceu na Guatemala, mas vive em Cuba. É fotógrafo e cineasta. Graduado pela Faculdade dos Meios de Comunicação pelo Instituto Superior de Artes (ISA). Colaborou com múltiplas revistas e documentou vários processos sociais, ecológicos e antropológicos vinculados a diversas instituições 
crianças)? Podemos também imprimir alguns frames dos filmes e misturá-los, dando concretude para essa aproximação num exercício de montagem, com a criação de novas histórias e encontros dentro das histórias originais.

- Tinho trabalha com diferentes atividades, cata mariscos e colhe caju. Laura ajuda a varrer o pátio de sua escola. E em nossa realidade? Fazemos algo parecido? Conhecemos crianças que trabalham ou que ajudam os adultos em seus afazeres? Inspirados em dois ou três planos dessas cenas, podemos filmar crianças de nossa comunidade na realização de pequenas tarefas.

- Em Una niña una escuela, vemos todo o trajeto de Laura desde casa até a escola. Ela acorda cedo, veste seu uniforme, vai a cavalo, atravessa rios e transita por pequenas veredas. A que horas acordamos? Qual transporte utilizamos? Como é o nosso caminho até a escola? Os alunos podem fotografar cinco imagens (ou filmar cinco planos fixos) de seu percurso desde casa até a escola.

- Experimentem ouvir a áudiodescrição do curta Carreto de olhos fechados, imaginando as cenas narradas. Escolham uma ou duas cenas do curta Una niña una escuela e gravem uma áudiodescrição dessas cenas. Pode-se, também, dividir o curta em pequenos pedaços entre a turma. Se cada grupo fizer uma pequena parte, teremos a audiodescrição do filme completo! Já pensou quantas pessoas se beneficiariam do resultado desse exercício?

- Ao colocar Stephanie dentro de seu carrinho de mão, Tinho dá uma nova função para esse objeto. Que outras funções podemos dar para objetos do nosso cotidiano? Para as ferramentas escolares por exemplo? Tentem desinventar os objetos, como diz o poeta Manoel de Barros? 0 que um lápis, um caderno, um apontador ou uma cadeira pode fazer para além das funções que já conhecemos?

- E como seria a imagem filmada de dentro do carrinho de Tinho onde está Stephanie? Procurem objetos móveis que possam servir de suporte para as crianças colocarem a câmera e filmarem um travelling. 0 que é um travelling? Pesquisem sobre esse e outros recursos do cinema.

- Na primeira cena de Carreto, vemos o reflexo de Tinho sobre um grande lago. Em cenas seguintes, vemos, novamente, Tinho "projetado" na areia molhada. Inspirados nessas cenas, procurem imagens parecidas em seu entorno e filmem os reflexos de colegas e objetos.

7 “[É preciso] desinventar os objetos. 0 pente, por exemplo. É preciso dar ao pente funções de não pentear. Até que ele fique à disposição de ser uma begônia. Ou uma gravanha. Usar algumas palavras que ainda não tenham idioma" (Barros, 2000, p. 176). 
- Em uma cena de Carreto, Stephanie se comunica com Tinho fazendo um pássaro de sombra com as mãos. A professora de Laura também brinca de fazer passarinhos com as mãos. Experimentem criar outros "seres" com o corpo e descubram como projetar sombras. Na Internet ${ }^{8}$, há pequenos vídeos de espetáculos de sombras que podem servir de inspiração e ajudar a introduzir a história dos primórdios do cinema, a qual começa com as pequenas brincadeiras de luz.

- Una niña una escuela termina informando que em Cuba há escolas para uma só criança. Isso pode ser uma motivação para estudar sobre esse país e sua história. Há, ainda, uma estátua que aparece na cena em que Laura varre o pátio da escola. De quem é? Procure nos filmes imagens disparadoras para novas perguntas e pesquisas.

- Tinho sobe num cajueiro. Como o diretor filma essa árvore? Que árvores temos perto da gente? Vamos escolher um plano dessa cena como dispositivo para filmar nossas árvores? Sabemos subir em árvores como Tinho? E se subirmos nas árvores e filmá-las lá de cima? Teríamos o "ponto de vista" da árvore? Como é o ponto de vista da mangueira, de uma amendoeira, de um abacateiro?

- Vemos diferentes atividades de Laura na escola, e em nossas escolas? 0 que fazemos? Tendo como referência essas cenas, escolham três planos para filmar o cotidiano de sua escola.

- Será que Laura se sente sozinha em uma escola só para ela? Já nos sentimos sozinhos? Como é a solidão? Como filmar a solidão? É possível se sentir sozinho mesmo em meio a outras pessoas? Ou, às vezes, é bom estar só? Converse com os alunos sobre isso. Tem algum lugar que você considera só seu? Que lugar é esse? Que tal cada um filmar esse cantinho especial?

- Veja os filmes muitas vezes, um depois do outro, um misturado no outro, e invente outras atividades!

\section{CRÉDITOS FINAIS}

No contexto da Lei 13.006/2014, do interesse crescente de educadores pelo trabalho com o audiovisual e do irreversível impacto das imagens na vida cotidiana, propomos pensar juntos a estética dos filmes vistos pelas crianças, nos filmes para a formação de professores, na tentativa de assegurar uma relação das crianças com o cinema, em diálogo com

8 Retirado de https://www.youtube.com/results?search_query=sombra+com+as+maos 
a diversidade das formas de vida, alimentando a discussão sobre o tipo de cinema que queremos produzir e exibir para a infância.

Diferentes autores vêm apontando características que podem ajudar nessa escolha do que exibir e consideramos que algumas delas foram contempladas nesta pequena seleção que fizemos. Girardello (2015) destaca quatro referências de curadorias a estarem presentes nos filmes para as crianças: os diferentes modos de ver a infância; a diversidade cultural brasileira (no que acrescentamos um diálogo com a América Latina); o jeito criança de ver e aprender o mundo; e a valorização da cultura tradicional na infância, com destaque para brincadeiras, ritmos e histórias locais.

Filmes que tratem com sutileza das coisas cotidianas da vida sem espetacularização e que não subestimem as crianças são pistas apontadas por Omelczuk (2016) recolhidas a partir de leituras de Walter Benjamin (2002) e de comentários da cineasta Sandra Kogut (2007) sobre a realização de seu filme Mutum. Mayor e Miranda (2015) e Oliveira (2015), ao pensarem os cinemas possíveis na educação, vêm sugerindo trabalhos que apontam para a dissolução da narrativa como principal forma de fruição audiovisual no sentido de uma relação artesanal com as imagens. Não tendo como meta a exclusividade de contar uma história, esse tipo de cinema visa, literalmente, a criar uma "experiência" com a câmera e com o mundo.

Diante de tantos recortes, os exercícios sugeridos ao final de nossa análise são apenas algumas possibilidades que vislumbramos com os filmes, amparados numa perspectiva que nos coloca em contato com a potência de criar realidades, interferir no mundo e aproximar contextos diferentes. Potência intrínseca a todas as artes e que a impressão de realidade das imagens em movimento torna ainda mais radical. Não se trata de uma cartilha a ser seguida, mas de um compartilhar da capacidade de autoria, de que nos apropriemos dos filmes, de suas histórias e das histórias da vida, que nos afetam, e de que concordemos ou discordemos recriando alternativas transformadoras.

\section{REFERÊNCIAS}

Agamben, G. (2007). Profanações. Boitempo.

Alea, T. (2009). Dialéctica del espectador. Ediciones EICTV.

Alegria, J., \& Duarte, R. (2008). Formação estética audiovisual: um outro olhar para o cinema a partir da educação. Revista Educação e Realidade, 33(1), 59-80.

Almacella, M. (2004). Educar con el cine. Ediciones Internacionales Universitarias.

Anderson, A. (Diretor). (2008). Una niña una escuela [Filme]. Cuba. https://www.youtube. $\mathrm{com} /$ watch?v=luCK5JrOMCl\&t=29s 
Austen, J. (2017). Sensatez y sentimientos. Lea S.A. Ediciones.

Bárcena, F. (2015). La diferencia (de los idiotas). Revista Pro-Posições, 26(1), 49-67.

Barros, M. (2000). O livro das ignorãças. Editora Record.

Benjamin, W. (2002). Reflexões sobre a criança, o brinquedo e a educação. Duas Cidades.

Bergala, A. (2008). A Hipótese-Cinema: Pequeno tratado de transmissão do cinema dentro e fora da escola (trad. M. Costa). Booklink e CINEAD-LISE-FE/UFRJ.

Bergala, A. (2012). Bom filme. Em A. Fresquet, \& C. Nanchery, Abecedário de cinema com Alain Bergala [vídeo]. LECAV, DVD.

Comolli, J. (2008). Ver e poder. Cinema, televisão, ficção, documentário. Universidade Federal de Minas Gerais.

Daney, S. (2007). A rampa. Cosac \& Naif.

De Oliveira, W. (2015). Uma educação e um cinema no terreno? 0 espacial e as imagens verdadeiras em Fernand Deligny e Cao Guimarães. Em A. Fresquet (Ed.), Cinema e Educação: A Lei 13.006 (pp. 120-131). Universo Produções.

Eisenstein, S. (2002). A forma do filme. Zahar.

Fresquet, A. (2013). Cinema e Educação: Reflexões e experiências com estudantes de educação básica, dentro e "fora" da escola. Autêntica Editora.

García, J. (1970). Por un cine imperfecto. Fondo Editorial Salvador de la Plaza.

Girardello, G. (2015). Encontrar, escolher e articular filmes brasileiros para crianças: Notas a partir de uma curadoria. Em A. Fresquet (Ed.), Cinema e Educação: A Lei 13.006 (pp. 187-195). Universo Produções.

Kogut, S. (Diretora). (2007). Mutum [Filme]. Brasil. (95 min).

Lei 13.006 (26 de junho de 2014). http://www.planalto.gov.br/ccivil_03/_Ato20112014/2014/Lei/L13006.htm

Marques, C. (produtor e diretor). Hughes, M. (diretora). (2009). Carreto [Filme]. Brasil: Coisa de Cinema.

Martínez-Salanova, E. (2002). Aprender con el cine, aprender de película. Una visión didáctica para aprender e investigar con el cine. Grupo Comunicar.

Mayor, A. \& Miranda, C. (2015). Fronteiras do imaginário: Cinema-poesia nas escolas de educação básica. Em A. Fresquet (Ed.), Cinema e Educação: A Lei 13.006 (pp. 132-139). Universo Produções. 
MINED. (2008). Ministerio de Educación de la República de Cuba. La Habana. https:// www.mined.gob.cu/

Omelczuk, F. (2016). 0 que se aprende quando se aprende cinema no hospital? (Tese de Doutorado), Universidade Federal do Rio de Janeiro, Brasil.

Rancière, J. (2009). A partilha do Sensível: estética e política. EXO experimental org, Editora 34.

Vilhaça, M. (2010). Cinema Cubano: Revolução e Política Cultural. Alameda. 